\title{
Article \\ Characteristics of Trees Infested by the Invasive Primary Wood-Borer Aromia bungii (Coleoptera: Cerambycidae)
}

\author{
Yuichi Yamamoto ${ }^{1, * \mathbb{D}}$, Yosuke Ishikawa ${ }^{2}$ and Kazuhiko Uehara ${ }^{3}$ \\ 1 Research Institute of Environment, Agriculture and Fisheries, Osaka Prefecture, 442, Shakudo, Habikino, \\ Osaka 583-0862, Japan \\ 2 Kobe Plant Protection Station, 1-1, Hatoba-cho, Chuo-ku, Kobe, Hyogo 650-0042, Japan; \\ yosuke_ishikawa310@maff.go.jp \\ 3 Biodiversity Center, Research Institute of Environment, Agriculture and Fisheries, Osaka Prefecture, 10-4, \\ Koyamoto-machi, Neyagawa, Osaka 572-0088, Japan; uehara@mbox.kannousuiken-osaka.or.jp \\ * Correspondence: YamamotoYu@mbox.kannousuiken-osaka.or.jp; Tel.: +81-072-958-6551
}

check for updates

Citation: Yamamoto, Y.; Ishikawa, Y.; Uehara, K. Characteristics of Trees Infested by the Invasive Primary

Wood-Borer Aromia bungii (Coleoptera: Cerambycidae). Insects 2022, 13, 54. https://doi.org/ $10.3390 /$ insects 13010054

Academic Editor: Francesco Nugnes

Received: 29 November 2021

Accepted: 30 December 2021

Published: 4 January 2022

Publisher's Note: MDPI stays neutral with regard to jurisdictional claims in published maps and institutional affiliations.

Copyright: (C) 2022 by the authors. Licensee MDPI, Basel, Switzerland. This article is an open access article distributed under the terms and conditions of the Creative Commons Attribution (CC BY) license (https:// creativecommons.org/licenses/by/ $4.0 /)$.
Simple Summary: The red-necked longhorn beetle Aromia bungii is an invasive species that causes damage to Rosaceae trees. In introduced countries, tree damage by A. bungii in many regions, such as orchards, forests, and ornamentals, is a serious problem. Information about the characteristics of pest-infested host trees is helpful for efficiently finding and controlling this beetle. In this study, we investigated the characteristics of infested and uninfested ornamental cherry trees in the field, and speculated as to the traits that are important to infestation. As a result, host trees with rough surface bark, large in size, and weakened conditions are prone to damage by A. bungii. These findings aid in the selection of trees or locations to be surveyed for intrusion detection surveillance, where a high probability of damage can be found, among many candidates in intruded areas. Moreover, this knowledge is useful for prioritizing preventive measures for host trees that are more likely to be attacked in already invaded areas.

Abstract: The expanding distribution and tree damage of the invasive, primary wood-borer Aromia bungii (Coleoptera: Cerambycidae), which kills trees of the Rosaceae family, is a problem in intruded areas. However, the tree characteristics associated with infestation by A. bungii, which are useful for early detection or prioritizing preventive measures, are not well examined. We investigated the presence or absence of tree damage (response variable) in pre- and post- surveys along with tree characteristics (four explanatory variables; bark roughness, size, species, and vigor) on monitoring trees in uninvaded sites (survey for the first trees to be damaged) and already invaded sites (survey for the next trees to be damaged). We evaluated the variables using generalized linear mixed models for each site (i.e., a first trees model and a next trees model). Three tree characteristics (bark roughness, size, and vigor) were included as explanatory variables in both best models, indicating that trees with rough surface bark, large in size, and weakened conditions were more susceptible to A. bungii infestation. The reasons for the difference between the two models (species was only chosen in the next trees model) will be considered in our future work.

Keywords: Aromia bungii; bark roughness; Cerambycidae; host preference; invasive species; rednecked longhorn beetle; Rosaceae; wood-borer; tree characteristics; tree vigor

\section{Introduction}

The red-necked longhorn beetle Aromia bungii (Faldermann, 1835; Coleoptera: Cerambycidae) is an invasive, primary wood-borer that damages trees of the Rosaceae family [1]. Its main hosts are Prunus armeniaca L. and Prunus persica (L.) Batsch in original regions [1]. In recent years, damage of trees, including other hosts such as Prunus domestica L., Prunus salicina Lindl., Prunus mume Siebold \& Zucc., and flowering cherry trees (Cerasus trees), 
by A. bungii in orchards, forests, and ornamental trees is a serious problem in the affected countries: Germany, Italy, and Japan [1-4].

To prevent the expansion of the distribution of exotic species and tree damage in introduced areas, early detection is critical [5]. A usual method for finding targets is monitoring surveys for intrusion detection based on the presence or absence of the species near the area where it was first discovered. In such surveillance programs, the use of synthetic pheromone lures, in combination with a trap apparatus to capture the beetles, have been conventionally employed against invaders, including exotic cerambycids beetles [6,7]. In addition, an attractant and sex-aggregating pheromone has been identified and artificially synthesized in A. bungii [8]. Moreover, studies on sex-specific chemoreceptivity on adult antennae [9] to volatile organic compounds from trees [10] that could be viable candidates for pheromone lure blends were conducted. However, the practical application of pheromone traps for the reconnaissance of adults remains a work in progress [11,12]. Therefore, adopting a fixed-point survey at potential points-of-entry [6] is currently one of the best means for early detection. When selecting suitable hosts and/or sites for an $A$. bungii invasion monitoring survey, information concerning the tree characteristics related to infestation can be helpful.

In relation to tree-boring cerambycid beetle infestations, previous studies have focused on tree characteristics, such as tree size [13-15], tree species [16], tree vigor [17-19], bark roughness [20,21], and micro-climate [22]. Recent observational reports have suggested that host trees that are larger in size [23-25], more mature [3], more stressed [3], and with rolled up or cracked bark [26] are more prone to being attacked by A. bungii; however, the factor and/or combinations of factors that decisively affect infestation in the field are unclear. Moreover, previous research on $A$. bungii have referred to tree conditions after damage by A. bungii having been found; in these studies, there is no denying the possibility that the condition of the infested trees was a result of the damage caused by the beetles [2]. Therefore, an early survey of tree characteristics is required before the effects of infestation become visible.

This study aimed to clarify the tree characteristics related to A. bungii infestation using ornamental cherry trees as monitoring trees in the field. We conducted a pre-survey for infestation, a survey for assessing tree characteristics (four variables: bark roughness, species, tree size, and tree vigor), and a post-survey for the infestation of monitoring trees planted in the field study sites (public parks). Then, we analyzed the characteristics of trees that were damaged and undamaged by A. bungii using generalized linear mixed models (GLMMs). We used two types of study site for this analysis, hence we conducted two GLMMs: (1) uninvaded sites for the model of the first trees to be damaged; and (2) already invaded sites for the model of the next trees to be damaged. Knowledge of the characteristics of the first trees to be damaged will aid in the selection of monitoring trees and sites for $A$. bungii intrusion detection. In addition, information about the characteristics of the next trees to be damaged may be useful in prioritizing the application of preventive control measures in intruded areas. Based on our results, we discuss the selections of each factor in the GLMMs from the view point of insect searching behavior, as well as the cause for differences between the models from the stand point of an invasion process related to propagule pressure.

\section{Materials and Methods}

\subsection{Study Sites and Monitoring Trees}

The research area was set in a region where an initial invasion of $A$. bungii was estimated to have occurred in Osaka Prefecture [27]. The area consisted of both industrial and residential areas. The host trees were planted in areas such as public parks, streets, personal residential properties; in these regions, the host trees were mainly ornamental cherry trees (Cerasus spp.), and small orchards (mainly P. mume) [24]. In our study, 49 public parks in the area were chosen as study sites; these parks each had four or more ornamental cherry trees (Figure 1). 


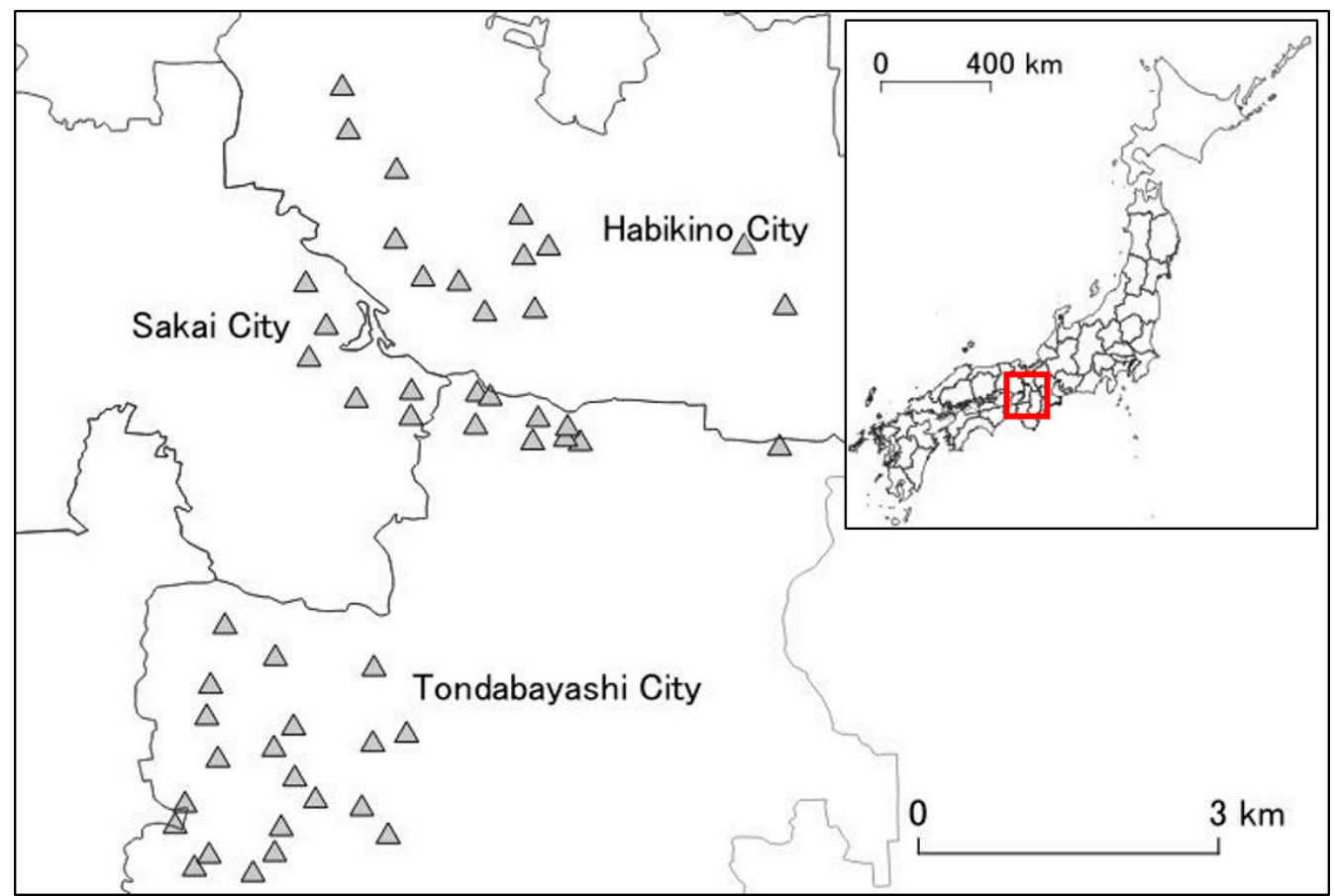

Figure 1. Research area and 49 study sites in Osaka Prefecture. The area spanned three cities in Osaka Prefecture (Habikino City, Sakai City, and Tondabayashi City). The shaded triangles represent the study sites. The map in the top right corner is a map of Japan's prefectures. Red rectangle represents the location of the research area (Osaka Prefecture).

All the ornamental cherry trees in each study site were established as monitoring trees. In 6 out of 49 survey points, where many flowering cherry trees had been planted, more than 25 trees that had been planted adjacent to each other were arbitrarily selected as monitoring trees.

\subsection{Survey of Infestation and Tree Characteristics}

In general, $A$. bungii has a 2-year life cycle in Japan and adults of $A$. bungii occur from June to August [2]. The larvae of a new generation, hatched from eggs laid by adults, will start to develop inside the host tree. During the hatching year, it is usually difficult to identify the infestation via larval frass ejection [28], which has been used as an indicator of infestation in field studies $[24,25,27]$, because annual larvae discharge tunneling frass at an undetectably small size and low volume. After the first overwintering inside the trees, $A$. bungii larvae resume feeding on the hosts and ejecting more visible frass. Therefore, the ejected frass noted during the adult emergence period (i.e., from June to August) is most likely due to the larvae born in the previous year.

Firstly, from July to August 2017, the initial survey for A. bungii infestation (hereafter referred to as the pre-survey) was conducted on each monitoring tree at all study sites, using the presence or absence of frass ejection as an indicator of infestation [27]. Other Cerambycidae species, such as Anoplophora chinensis (Forster) (Coleoptera: Cerambycidae) and Aegosoma sinicum White (Coleoptera: Cerambycidae), also infest living flowering cherry trees with larval frass emission [29]. Infestation by A. bungii larvae was identified based on the particle shape of the frass [29-31] ejected from the monitoring trees.

Secondly, from September to October 2017, three characteristics were noted in the monitoring trees in the same study location: (1) bark roughness, (2) tree size, and (3) tree vigor. Bark roughness on tree trunks at a height of less than $2 \mathrm{~m}$ from the ground, where most ornamental cherry trees were damaged [24], was classified into three categories based on the degree of unevenness and cracking of the surface bark, according to visual inspection: (1) smooth, (2) intermediate, or (3) rough (Figure 2). Tree size was measured 
as the diameter $(\mathrm{cm})$ of tree trunks at about $10 \mathrm{~cm}$ in height from the ground. Tree vigor was rated visually and categorized into five levels based on the attachment of leaves in the crown, with reference to the rating by Hishinuma et al. [32]: level 1, about 75\% and more leaf area loss; level 2, about 50\% loss; level 3, about 25\% loss; level 4, about $10 \%$ loss (no tip leaves compared to level 5); and level 5, no loss (fully covered with leaves to tips). Additionally, trees with no crown leaves were treated as dead, classified as level 0 for convenience, and excluded from the analyses.

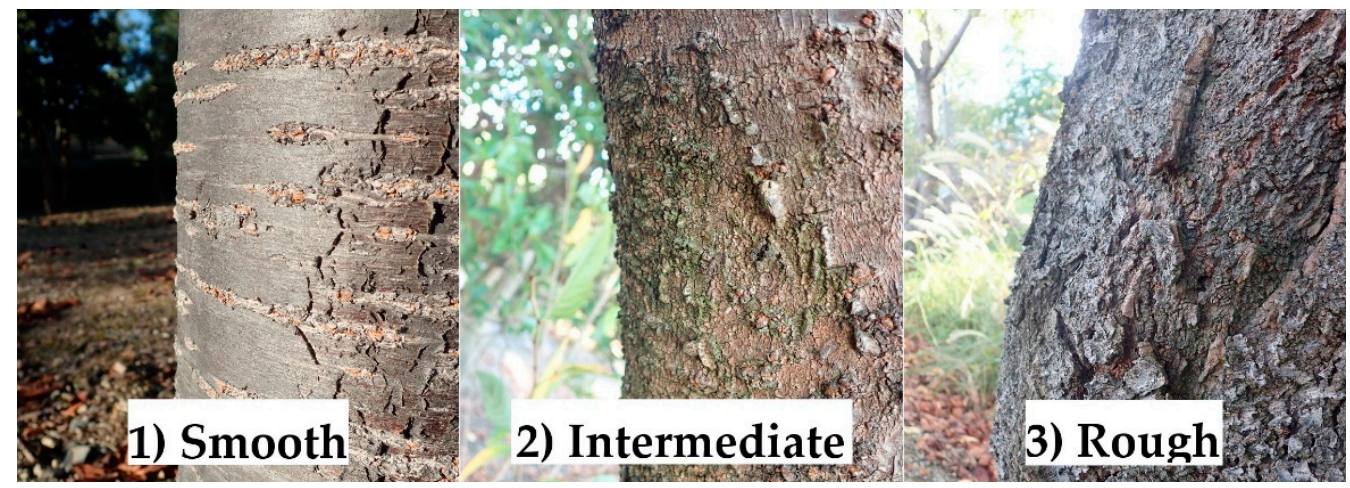

Figure 2. Three categories of tree trunk bark roughness based on the degree of uneveness and cracking of the surface bark, as assessed via visual inspection. All pictures are of Cerasus $\times$ yedoensis 'Somei-yoshino'.

Thirdly, in April 2018, the species, races, or cultivars (hereafter referred to as a species) of all monitoring trees, as the fourth tree characteristic, were identified during the cherry blossom season (mainly April in Japan) in all study sites. Species categorization was based on the morphology of both the flowers and leaves of the monitoring trees with main reference to the picture book by Oohara [33]. When classification was not possible using the two morphological indexes, the tree species were categorized as a cultivar group named the 'C. Sato-zakura group' [34].

Lastly, in August 2018, a resurvey for A. bungii infestation (hereafter referred to as the post-survey) was performed on the monitoring trees at all study sites, one year after the pre-survey, using the same methods [27].

\subsection{Trees of Interest by Study Site Category}

Table 1 shows the categories of study sites in terms of the presence or absence of $A$. bungii larvae frass ejection on the monitoring trees during the pre- and/or post-survey. Category 1 is a combination of the absence of larval frass ejection in the pre-survey and presence in the post-survey (Table 1). Similarly, Category 2 is the combination of "absence" and "absence", Category 3 is that of "presence" and "presence", and Category 4 is that of "presence" and "absence" in the pre- and post-surveys, respectively (Table 1). Categories 1 and 2 corresponded to parts of uninvaded areas; each monitoring tree in Category 1 was used for an analysis of the first trees to be damaged in uninvaded areas (Table 1). Categories 3 and 4 corresponded to parts of already invaded areas; each monitoring tree in Category 3 was used for an analysis of the next trees to be damaged in already invaded areas (Table 1). The "absence" study sites of both Categories 2 and 4 in the post-survey were not included in this study because we could not assess whether $A$. bungii adults had invaded those study sites in the year of the pre-survey. 
Table 1. Study site category by presence or absence of a tree infested by Aromia bungii and the total number of monitoring trees with and without infestation in each study site category. Pre-survey was the first survey on monitoring trees to classify them as infested or uninfested trees. Post-survey was the second survey on the monitoring trees, which were uninfested in the pre-survey, to categorize them as infested or uninfested trees.

\begin{tabular}{|c|c|c|c|c|c|c|c|c|}
\hline \multirow{2}{*}{$\begin{array}{l}\text { Category } \\
\text { of } \\
\text { Study Site }\end{array}$} & \multicolumn{2}{|c|}{$\begin{array}{l}\text { Infested Trees } \\
\text { in Study Site }\end{array}$} & \multirow{2}{*}{$\begin{array}{c}\text { Total } \\
\text { Number of } \\
\text { Study Sites }\end{array}$} & \multicolumn{4}{|c|}{ Number of Trees } & \multirow{2}{*}{$\begin{array}{c}\text { Total } \\
\text { Number of } \\
\text { Monitoring } \\
\text { Trees }\end{array}$} \\
\hline & $\begin{array}{c}\text { In } \\
\text { Pre-Survey }\end{array}$ & $\begin{array}{c}\text { In } \\
\text { Post-Survey }\end{array}$ & & $\begin{array}{c}\text { Infested } \\
\text { in } \\
\text { Pre-Survey }\end{array}$ & $\begin{array}{c}\text { Infested } \\
\text { in } \\
\text { Post-Survey }\end{array}$ & $\begin{array}{l}\text { Uninfested } \\
\text { in } \\
\text { Post-Survey }\end{array}$ & $\begin{array}{c}\text { Cut or Dead } \\
\text { before } \\
\text { Post-Survey }\end{array}$ & \\
\hline 1 & Absence & Presence & 12 & 0 & 85 & 304 & 4 & 393 \\
\hline 2 & Absence & Absence & 13 & 0 & 0 & 182 & 3 & 185 \\
\hline 3 & Presence & Presence & 22 & 132 & 105 & 171 & 9 & 417 \\
\hline 4 & Presence & Absence & 2 & 14 & 0 & 22 & 1 & 37 \\
\hline
\end{tabular}

\subsection{Data Processing for Statistical Analysis}

In terms of tree vigor, trees in the crown rating level 1 were integrated into level 2 since the sample size of level 1 was small. In terms of species, trees categorized as any species other than the top three most frequent classifications were included into the C. Sato-zakura group; thus, the monitoring trees were grouped into four species; "C. jamasakura," "C. Sato-zakura group," "C. speciosa," and "C. $\times$ yedoensis 'Somei-yoshino'" (Appendices A and B). Four trees in study site category 1 and the nine trees in study site category 3 were dead (tree vigor: level 0) or cut prior to the post-survey; these trees were excluded from the statistical analysis (Table 1 ).

\subsection{Statistical Analysis}

All statistical analyses were performed in R version 4.0.3 [35] using the packages "car," "emmeans," "lme4," "MASS," "mgcv," "multcomp," and "MuMIn." Both "ggeffect" and "ggplot2" were used to plot the data.

To examine the tree characteristics of both the first (category 1) and next (category 3) trees to be damaged (i.e., in separate models, and hereafter referred to as the first trees model and the next trees model, respectively), we applied a generalized linear mixed model (GLMM: "glmer" function of the "lme4" package) with a log-link function to explain the presence or absence of $A$. bungii larvae frass ejection on the monitoring trees, as an indicator of infestation (response variable). The probability distribution of the response variable was assumed to be a binomial distribution. The explanatory variables in the full model were as follows: tree size (continuous variable), bark roughness (three levels as ordered categorical variables; smooth < intermediate < rough), tree vigor (four levels as ordered categorical variables; crown rating level $2<$ level $3<$ level $4<$ level 5), species (four groups as a categorical variable: "C. jamasakura," "C. Sato-zakura group," "C. speciosa," and "C. $\times$ yedoensis 'Somei-yoshino'"). Note that there was a positive polyserial correlation between tree size and bark roughness in the first trees model $(\rho=0.54)$ and the next trees model ( $\rho=0.51$; "polyserial" function of the "polycor" package); we included both variables in the full models and checked the multicollinearity of these variables in the selected models (GLMMs) using the variance inflation factor (VIF; "check collinearity" function of the "performance" package).

First, we conducted a preliminary analysis for the selection of random effect terms based on the full model using the restricted maximum likelihood method, considering "tree size" and "study site" with the following random variable: (1) random intercept (study site), (2) random slope (tree size by study site), (3) independent random intercept and slope, and (4) correlated random intercept and slope. The model with the smallest Akaike's information criterion (AIC) value [36] was selected as the most predictive model ("AIC" function of the "stats" package). The results of the model selection for random effects are shown up to the models with the second smallest AIC value (e.g., Table 2). 
Table 2. Results of the preliminary selection of random effect terms in generalized linear mixed models (GLMMs) for tree infestation by Aromia bungii in uninvaded areas.

\begin{tabular}{ccc}
\hline Rank & Random Effect Term & $\Delta$ AIC \\
\hline 1 & Slope (tree size) by study sites & 0 \\
2 & Independent intercept and slope (tree size) by study site & 0.44 \\
\hline $\begin{array}{l}\text { Explanatory variables in the GLMM (full model): bark roughness + species + tree size + tree vigor. AIC, Akaike's } \\
\text { information criterion; GLMM, generalized linear mixed model. }\end{array}$
\end{tabular}

Next, we performed model selection for explanatory variables on the full model, with the random effect selected from the above preliminary analysis using maximum likelihood methods. The most predictive model was chosen among the models with all combinations of the explanatory variables ("dredge" function of "MuMIn" package) according to the smallest AIC value. The results of the model selection for explanatory variables, with the coefficients of continuous variables, are shown up to the models with the second lowest AIC value (e.g., Table 3). In terms of the fixed effects in the best model, the Wald's II Chi-squared test was conducted ("ANOVA" function of the "car" package) for Chi-squared values and $p$-values were used to analyze the effect of each variable on the response variable. In addition, an ANOVA test was performed on the fixed effects to calculate the mean square for variance of the explanatory variables in the models.

Table 3. Results of model selection by AIC and parametric coefficients of GLMMs, based on the preliminary selection in Table 2.

\begin{tabular}{|c|c|c|c|c|c|c|c|c|c|}
\hline \multirow{2}{*}{ Rank } & \multirow{2}{*}{$\Delta \mathrm{AIC}$} & \multicolumn{2}{|c|}{$\mathbf{R}^{2}$} & \multicolumn{5}{|c|}{ Regression Coefficient } & \multirow{2}{*}{$\begin{array}{c}\begin{array}{c}\text { Standard Deviation } \\
\text { of Coefficient }\end{array} \\
\text { Tree Size } \\
\text { (Random Slope) }\end{array}$} \\
\hline & & Conditional & Marginal & $\begin{array}{c}\text { Bark } \\
\text { Roughness }\end{array}$ & Species & Tree Size & Tree Vigor & Intercept & \\
\hline 1 & 0 & 0.567 & 0.307 & + & - & 0.079 & + & -4.054 & 0.035 \\
\hline 2 & 0.65 & 0.529 & 0.275 & + & - & 0.069 & - & -4.069 & 0.033 \\
\hline
\end{tabular}

Plus (+) and minus (-) symbols indicate that the categorical variable was selected and not selected in the model respectively. AIC, Akaike's information criterion; GLMM, generalized linear mixed model.

Lastly, we estimated the marginal mean \pm 1 standard error (SE) for the fixed effects of the categorical variables in the best model, on a log odds ratio scale ("emmeans" function of the "emmeans" package). Then, we performed a multiple comparison on the difference of the estimated marginal means (EMMs) between the levels within each fixed effect using the Tukey-Kramer honestly significant difference (HSD) test $(p<0.05)$; "pairs" function applied to EMMs) and the results were plotted on a response scale (probability) using values back-transformed from the log odds ratio scale.

\section{Results}

\subsection{Number of Study Sites and Monitoring Trees Categorized by A. bungii Infestation}

Table 1 shows the total number of study sites and monitoring trees with or without infestation in the pre- and post-surveys, according to the study site category. The infested or uninfested monitoring trees in the post-survey were treated as the presence or absence data (response variable) for infestation in the first trees model (GLMM; 85 infested trees and 304 uninfested trees in the Category 1 study sites) and in the next trees model (GLMM; 105 infested trees and 171 uninfested trees in the Category 3 study sites; Table 1).

The total number of monitoring trees with or without infestation in the pre- and postsurvey is presented according to tree characteristics (after data processing) in Appendix A and according to species (prior to data processing) in Appendix B.

\subsection{First Trees Model}

In the preliminary analysis for the selection of random effects in the first trees model, we selected the random slope model for tree sizes by study site (Table 2). Next, the 
best model (GLMM) for tree infestation, selected according to the AIC value, included the following explanatory variables: bark roughness, tree size, and tree vigor. These three variables (bark roughness, tree size, and tree vigor) did not have multicollinearity $(\mathrm{VIF}=1.13,1.17$, and 1.12, respectively). The estimated curve and recorded value by combinations of each level on the fixed effects in the first trees model are shown in Figure 3. The partial regression coefficient for the variable tree size was positive (coefficient $=0.079$ ) in the best model (Table 3), indicating that larger ornamental cherry trees are more susceptible to $A$. bungii infestation, as shown in Figure 4 . The mean trunk circumference was $48.6 \pm 14.9 \mathrm{~cm}$ in infested trees and $33.4 \pm 15.2 \mathrm{~cm}$ in uninfested trees $(36.7 \pm 16.4 \mathrm{~cm}$ across all monitoring trees). The smallest and largest trunk circumferences at the bottom of infested trees were 14 and $102 \mathrm{~cm}$, respectively. The ordered, categorical variable bark roughness had a positive effect on infestation in the order of the levels (Figure 3). On the other hand, the other ordered, categorical variable tree vigor had a negative effect on infestation in the order of the levels (Figure 3). The results of the parametric coefficients for the categorical variables in the GLMM are shown in Table 3 and Appendix C. The mean squares for variance and Chi-square values of each fixed effect, based on the best model, are shown in Appendix D.

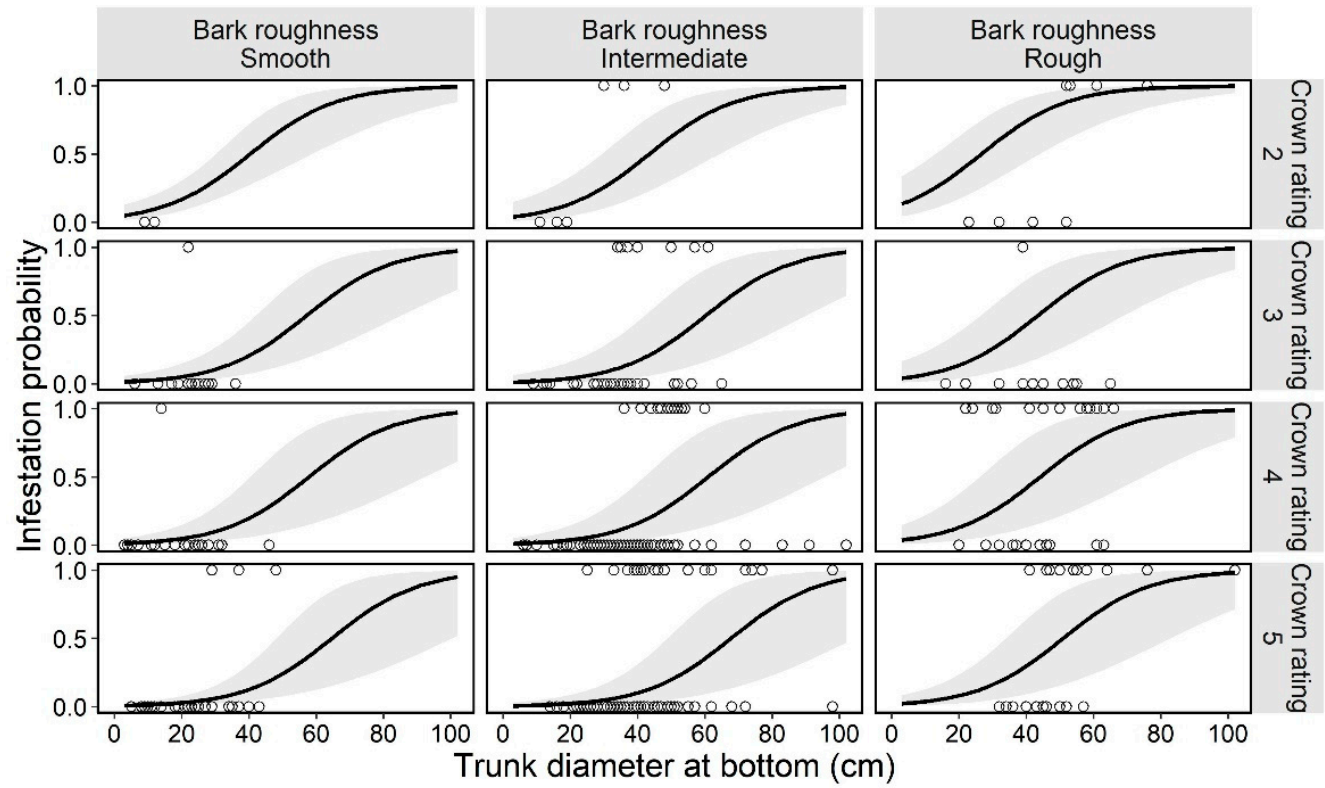

Figure 3. Estimated curve (GLMM) of the probability of an ornamental cherry tree being infested by Aromia bungii, in combination with two tree characteristics: bark roughness and tree vigor (crown rating; more vigorous with the numbers) in uninvaded areas. Open circles reflect the recorded value of a monitoring tree for infestation (1) or no infestation (0) in the infestation survey. The shaded area represents the $95 \%$ confidence intervals of the mean probability of infestation, without considering the influences of the random effect (random slope for tree size by study site) on the GLMM.

The marginal means \pm 1 SEs of each level for the variable bark roughness on a log odds ratio scale were $-1.441 \pm 0.670$ for the smooth level, $-1.687 \pm 0.467$ for the intermediate level, and $-0.362 \pm 0.521$ for the rough level (Figure 4: back-transformed from the $\log$ odds ratio scale for the mean $\pm 1 \mathrm{SE}$ ). When comparing the marginal mean probability of infestation between the bark roughness levels, we only found a significant difference between the intermediate and rough levels (Tukey HSD test, difference in the means $=1.325$, $p<0.05)$; there were no other differences between any other levels ( $p>0.05$; Figure 4$)$. The marginal means for tree vigor, on a log odds ratio scale, were $-0.010 \pm 0.786$ for level $2,-1.335 \pm 0.552$ for level $3,-1.387 \pm 0.485$ for level 4 , and $-1.922 \pm 0.488$ for level 5 (Figure 4: back-transformed from the log odds ratio scale for the mean $\pm 1 \mathrm{SE}$ ). When comparing the marginal mean probability of infestation between tree vigor levels, there 
were no differences between all levels (Tukey HSD test, $p>0.05$ ); however, the value of the lowest (level 2) and highest levels (level 5) tended to be different (Tukey HSD test, difference in the means $=1.913, p=0.056$ ).

(A) Bark roughness

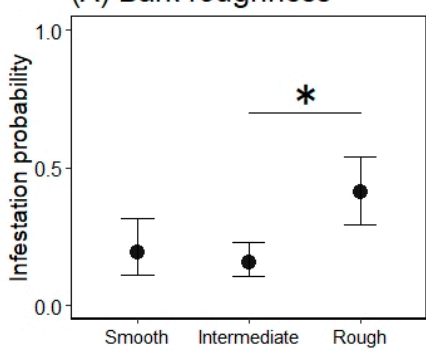

(B) Tree Size

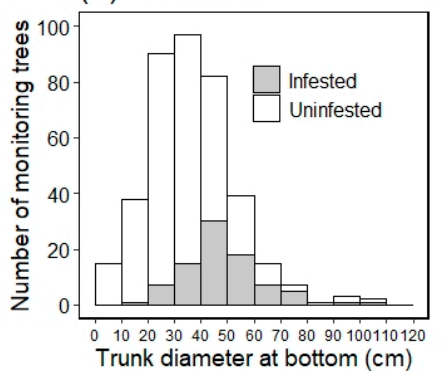

(C) Tree vigor

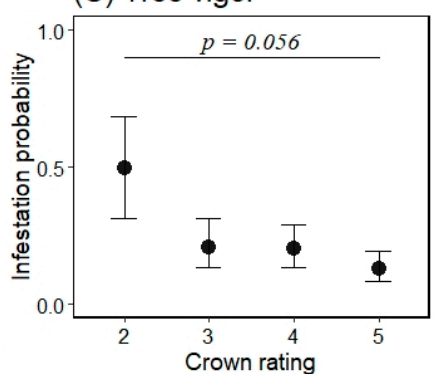

Figure 4. Marginal mean for the probability of an ornamental cherry tree being infested by Aromia bungii based on bark roughness (A) and tree vigor (C), and a histogram of the continuous variable tree size (B) for infestation (1) or no infestation (0) in uninvaded areas. Filled circles represent mean values and the bars extending from the circles represent the standard error (SE) of the means (A,C; back-transformed from the log odds ratio scale for the mean $\pm 1 \mathrm{SE}$ ). Shaded areas represent infested trees and open areas represent uninfested trees in the infestation survey (B). * indicates a significant difference in the mean probability of infestation between the levels of the indicated bars (Tukey-Kramer HSD test: $p<0.05)$.

\subsection{Next Trees Model}

In the preliminary analysis for the selection of random effects in the next trees model, we selected the random slope model for tree size by study site (Table 4). Next, the best model (GLMM) for tree infestation, selected according to the AIC value, included the following explanatory variables: bark roughness, species, tree size, and tree vigor (Table 5). These four variables (bark roughness, species, tree size, and tree vigor) did not have multicollinearity (VIF $=1.20,1.11,1.30$, and 1.33, respectively). The estimated curve and recorded value by combinations of each level on the fixed effects are shown for $C . \times$ yedoensis 'Somei-yoshino' as it is representative of most planted species in the study sites (Appendix B) in Figure 5. The partial regression coefficient for the variable tree size was positive (coefficient $=0.08$; Table 5), indicating that larger ornamental cherry trees are more susceptible to A. bungii infestations, like in the first trees model. The mean trunk circumference was $37.2 \pm 13.6 \mathrm{~cm}$ in infested trees and $25.9 \pm 11.8 \mathrm{~cm}$ in uninfested trees $(30.2 \pm 13.6 \mathrm{~cm}$ across all the monitoring trees). The smallest and largest trunk circumferences at the bottom of infested trees were 13 and $78 \mathrm{~cm}$, respectively. The ordered, categorical variable bark roughness had a positive effect on infestation in the order of the levels (Figure 5). On the other hand, the ordered, categorical variable tree vigor had a negative effect on infestation in the order of the levels. The results of parametric coefficients for the categorical variables in the GLMM are shown in Table 5 and Appendix E. The mean squares for variance and Chi-square values of each fixed effect, based on the best model, are shown in Appendix F.

Table 4. Results of the preliminary selection of random effect terms on GLMMs for tree infestation by Aromia bungii in invaded areas.

\begin{tabular}{ccc}
\hline Rank & Random Effect Term & $\Delta$ AIC \\
\hline 1 & Slope (tree size) by study sites & 0 \\
2 & Independent intercept and slope (tree size) by study sites & 2.00 \\
\hline
\end{tabular}

Explanatory variables in the GLMM (full model): bark roughness + species + tree size + tree vigor. AIC, Akaike's information criterion; GLMM, generalized linear mixed model. 
Table 5. Results of model selection by AIC and parametric coefficients of GLMMs, based on the preliminary selection in Table 4.

\begin{tabular}{cccccccccc}
\hline & & \multicolumn{3}{c}{$\mathbf{R}^{2}$} & & \multicolumn{2}{c}{ Regression Coefficient } & \multicolumn{2}{c}{$\begin{array}{c}\text { Standard Deviation } \\
\text { of Coefficient }\end{array}$} \\
\cline { 3 - 10 } Rank & $\mathbf{\Delta}$ AIC & Conditional & Marginal & $\begin{array}{c}\text { Bark } \\
\text { Roughness }\end{array}$ & Species & Tree Size & Tree Vigor & Intercept & $\begin{array}{c}\text { Tree Size } \\
\text { (Random Slope) }\end{array}$ \\
\hline 1 & 0 & 0.471 & 0.382 & + & + & 0.083 & + & -2.689 & 0.022 \\
2 & 1.83 & 0.481 & 0.338 & + & - & 0.089 & + & -2.632 & 0.029 \\
\hline
\end{tabular}

Plus (+) and minus (-) symbols indicate that the categorical variable was selected and not selected in the model respectively. AIC, Akaike's information criterion; GLMM, generalized linear mixed model.

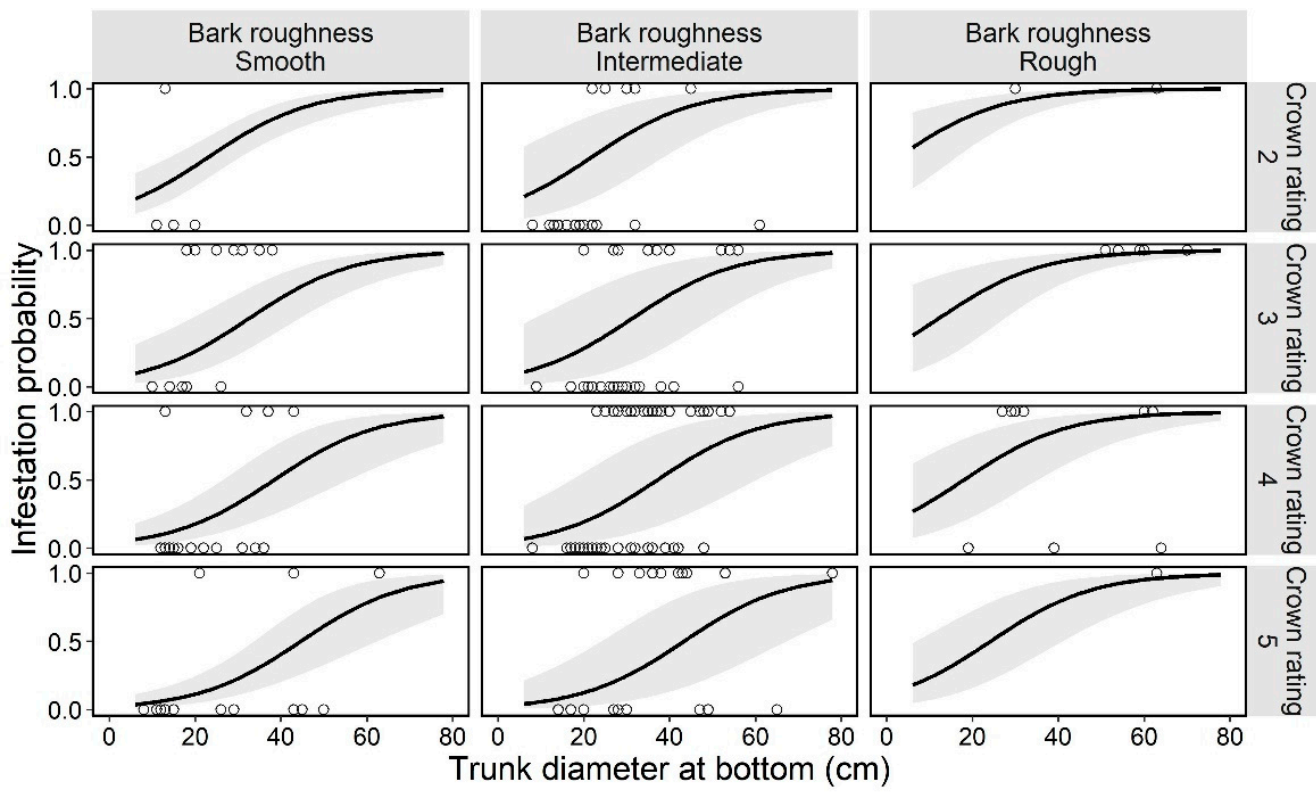

Figure 5. Estimated curve (GLMM) of the probability of an ornamental cherry tree being infested by Aromia bungii, in combinations with two tree characteristics: bark roughness and tree vigor (crown rating; more vigorous with the numbers) in Cerasus $\times$ yedoensis 'Somei-yoshino' in already invaded areas. Open circles represent the recorded value of a monitoring tree for infestation (1) or no infestation (0) in the infestation survey. Shaded areas represent the $95 \%$ confidence intervals of mean probability of infestation, without considering the influences of the random effect (random slope for tree size by study site) on the GLMM.

The marginal means \pm 1 SEs of each level for bark roughness on a log odds ratio scale were $-1.271 \pm 0.479$ for the smooth level, $-1.110 \pm 0.369$ for the intermediate level, and $0.488 \pm 0.673$ for the rough level (Figure 6: back-transformed from the log odds ratio scale for the mean $\pm 1 \mathrm{SE}$ ). When comparing the marginal mean probability of infestation between the bark roughness levels, values for the smooth and rough levels were significantly different (Tukey HSD test, difference in the means $=1.704, p<0.05$ ), as were those for the intermediate and rough levels (difference in the means $=1.598$, $p<0.05)$; however, the smooth and intermediate levels were the same $(p>0.05$; Figure 6). The marginal means for species, on a log odds ratio scale, were $-1.862 \pm 1.005$ for $C$. jamasakura, $-0.685 \pm 0.522$ for the C. Sato-zakura group, $-0.167 \pm 0.631$ for C. speciosa, and $0.235 \pm 0.315$ for $C . \times$ yedoensis 'Somei-yoshino' (Figure 6: back-transformed from the log odds ratio scale for the mean $\pm 1 \mathrm{SE}$ ). When comparing the marginal mean probability of infestation between the groups of species, there were no differences between any groups (Tukey HSD test, $p>0.05$; Figure 6 ). The marginal means for tree vigor, on a log odds ratio scale, were $0.351 \pm 0.562$ for level $2,-0.435 \pm 0.465$ for level $3,-0.926 \pm 0.425$ for level 4 , and $-1.441 \pm 0.531$ for level 5 (Figure 6: back-transformed from the log odds ratio scale for the means $\pm 1 \mathrm{SEs})$. When comparing the marginal mean probability of infestation 
between tree vigor levels, the values for level 2 were different from those for level 5 (Tukey HSD test, difference in the means $=1.792, p<0.05$ ), and all other levels were similar $(p>0.05$; Figure 6); however, the values of the lowest level (level 2$)$ and the second highest level (level 4) tended to be different (Tukey HSD test, difference in the means $=1.277$, $p=0.058$; Figure 6).

(A) Bark roughness

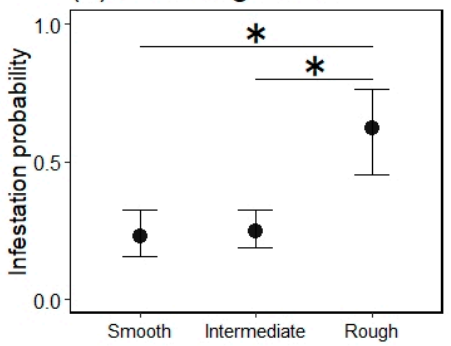

(B) Species

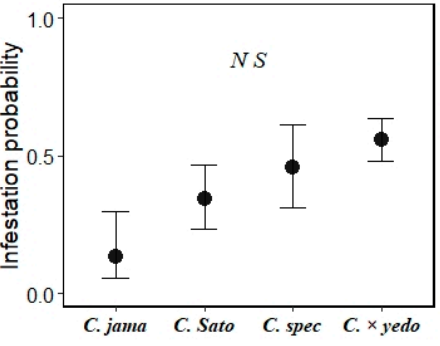

(C) Tree size

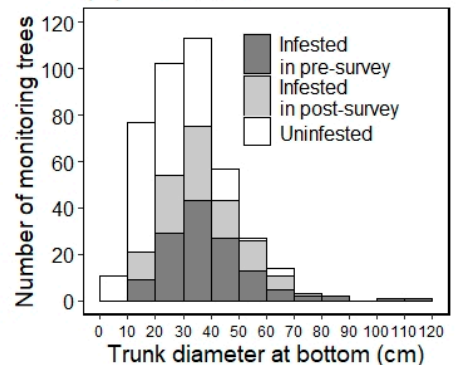

(D) Tree vigor

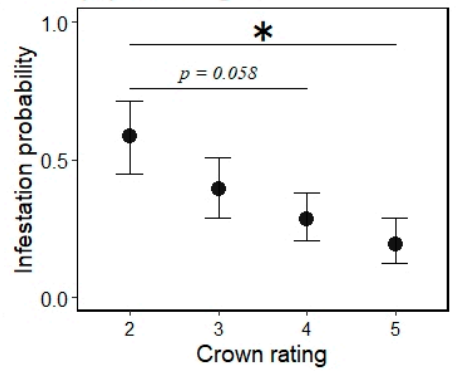

Figure 6. Marginal mean of monitoring trees being infested by Aromia bungii based on bark roughness (A), species (B), and tree vigor (D), and a histogram of the continuous variable tree size (C) for infestation (1) or no infestation (0) in invaded areas. Filled circles represent mean values and bars extending from the circles represent the standard errors (SEs) of the means (A,B,D; back-transformed from the $\log$ odds ratio scale for the mean $\pm 1 \mathrm{SE}$ ). C. jama, C. Sato, C. spec, and C. $\times$ yedo are abbreviations for Cerasus jamasakura, C. Sato-zakura group (including all species other than these three species), C. speciosa, and C. $\times$ yedoensis 'Somei-yoshino', respectively. Dark shaded areas represent infested trees observed in the pre-survey for infestation, light shaded areas represent infested trees, and open areas represent uninfested trees in the post-survey for infestation (C). ${ }^{*}$ indicates a significant difference in the mean probability of infestation between the levels of the indicated bars $(p<0.05)$. $N S$ indicates no significant difference between the means of each level (Tukey-Kramer HSD test: $p>0.05)$.

\section{Discussion}

We accounted for the characteristics related to infestation susceptibility of host trees by the invasive, primary wood-borer A. bungii using two GLMMs-a model for the first trees to be damaged in uninvaded areas and a model for the next trees to be damaged in already invaded areas - based on the presence or absence of frass ejection on each monitoring tree in field surveys. The two GLMMs had three explanatory variables in common (bark roughness, tree size, and tree vigor), with significant coefficients (except for tree vigor in the first trees model; Appendix D and F), and the same random effect (random slope of tree size by study site; Tables 2 and 3). Moreover, each explanatory variable showed the same directional influences in both models (Figures 3 and 5). Therefore, these three characteristics can be an important determinant for A. bungii infestation in host trees.

We showed that larger trees were more susceptible to infestation. Previous research on other Cerambycidae beetles also reported that infested host trees were larger in size [14,15,37]. In terms of host selections, in the case of Tetropium fuscum (Fabricius) (Coleoptera: Cerambycidae), tree size positively affects the landing rate; this relationship is thought to be due to the difference in the chances of adults being passively intercepted on larger versus smaller trees [15]. This passive effect related to tree size is also suggested in the mathematical model for encounter rates in the process of random searching for host trees in tree-boring bark beetles [38]. Conversely, adult females of Semanotus japonicus Lacordaire (Coleoptera: Cerambycidae) make inter-tree movements by preferentially selecting the larger trees in a patch, and also exhibit more frequent residence, resulting in more occurrences of adults of the next generation on the trees [13]. As for A. bungii, there are no reports about random or selective behavior on host trees in the field. It may also be important to consider the invasion process with respect to host selection. The attraction of cerambycids to host trees is thought to occur by host volatiles on a patch scale, then random landing among host 
trees within a patch would occur after being introduced [18]. Therefore, it may be better to examine the process-(1) entering a patch and (2) landing or ovipositing on a single-tree in a patch-through which $A$. bungii adults can behave randomly or selectively. In future studies, both the mechanism for the selection of invasion patches among uninvaded patches and the mechanism for the infestation of larger trees within a selected patch should be assessed; identifying these mechanisms would provide useful information for selecting the most appropriate sites and trees for monitoring the invasion of $A$. bungii. As a supplementary note, the effect size of the variable (tree size) varies among study sites, as suggested by the selection of the random slope models for tree size. The SD for tree size on the random slope coefficients in the next trees model (0.022) was slightly smaller than that in the first trees model (0.035; Tables 3 and 5); this may be partly related to differences in the distribution of tree sizes under attack by $A$. bungii adults because larger trees had already been infested (Figure 6), whereas smaller trees were used as monitoring trees for analysis in the next trees model (the mean \pm SD of trunk circumference: $36.7 \pm 16.4 \mathrm{~cm}$ in the first trees model versus $30.2 \pm 13.6 \mathrm{~cm}$ in the next trees model).

Our results suggest that trees with rough surface bark are more susceptible to infestation by A. bungii (Figures 3 and 5). Considering that adult females oviposit in the crevices of bark [1], trees with smooth surface bark (i.e., few crevices) would not have suitable sites for oviposition, whereas trees with rough surface bark would have suitable sites. Besides, trees with smooth tree bark may avoid beetle attacks by reducing the insect's ability to grip onto the surfaces of the trees (slippery hypothesis) [39]. A. bungii females may have difficulty crawling and/or residing on smooth surface trees while searching for appropriate egg-laying sites. On the other hand, the mean infestation probability was similar for the smooth and intermediate levels, based on our visual assessment of bark (Figures 4 and 6); this lack of a difference may be due to the partial coverage of intermediate monitoring trees with smooth bark, which can significantly reduce the number of total attacks by bark beetles [39]. Hence, entire coverage with a rough surface may increase the risk of infestation by A. bungii. Further experiments are required to identify the cut-off point for the ratio of rough surface bark on tree surfaces.

With regards to tree vigor, $A$. bungii can cause damage to trees in various conditions: from obviously healthy trees (crown rating: level 5) to weakened trees (crown rating: level 2; recorded values in Figures 3 and 5). This ecological feature of A. bungii as a primary wood-borer may classify it as a highly invasive pest [40]. Moreover, our results suggest that the infestation rate of $A$. bungii increased as the tree vigor decreased (Figures 4 and 6). The high damage rate on weakened trees may suggest that tree vigor is related to some infestation process; weakened trees may be selectively chosen as a landing site by $A$. bungii and/or weakened trees (chosen randomly) may be more susceptible to infestation because of the physiological effect of tree decline. Nonetheless, we were unable to assess the process after landing in this study.

Species was differentially selected for inclusion in the first trees model (not selected) and the next trees model (selected; Tables 3 and 5). Moreover, in the next trees model, species was chosen as an explanatory variable, which did not have a significant effect on the model (Appendix F) and the mean infestation probability among species categories was not different (Figure 6). There are no reports for differences in A. bungii infestations among ornamental cherry trees species in the field. When including host species other than ornamental cherry trees, the damage rate of ornamental cherry trees was much lower than that of peach trees (P. persica) in the vicinity of a peach orchard, despite the fact that the ornamental cherry trees were larger than the peach trees [23]. In a study of the invasive tree-boring Cerambycidae beetle Anoplophora glabripennis (Motschulsky), the host species strongly affected infestation in both the field and laboratory experiments [41]. There is a lack of clear evidence for differences in the susceptibility to $A$. bungii infestation between host species; therefore, further research is necessary, both in the field and in laboratory studies.

Upon consideration of the values for the conditional coefficient of determination $\left(R^{2}\right)$ in the best models (Tables 3 and 5), some factors may explain the residual variations of the 
models. In the process of the invasion of non-native species, the probability of success for intrusion into new regions increases with both the size of a set of individuals released and the number of release events - this is called propagule pressure [5]. Scaling this process down and applying it to our research scheme, the establishment of $A$. bungii infestation in monitoring trees could also be influenced by propagule pressure. In our study, we assumed that the monitoring trees in the first trees model were under a lower propagule pressure derived from uninvaded sites, whereas the monitoring trees in the next trees model were under a higher propagule pressure derived from the already invaded sites. If so, the difference in both the selection and statistical significance of the variable (e.g., species and tree vigor) may become apparent when propagule pressure varies. In this study, we did not include such indexes for propagule pressure because we were unable to monitor or determine the number and frequency of visits by adult females on monitoring trees. Verification of the models upon inclusion of indexes for propagule pressure is our future challenge.

In summary, using field studies and GLMMs, we showed that the tree characteristics of bark roughness, tree size, and tree vigor could be important indexes for susceptibility to infestation by the primary wood-borer A. bungii. Trees with rough surface bark, that are larger in size, and have a weakened condition were more susceptible to infestation. This knowledge aids in the selection of monitoring sites and trees for the detection of $A$. bungii intrusion in undiscovered areas (by the first trees model) and to prioritize trees for the application of preventive control measures in already invaded locations (by the next trees model). Moreover, there are other potential, influencing factors for A. bungii infestation, such as host tree species and propagule pressure; our future research will examine the effect of these factors on the infestation process.

Author Contributions: Conceptualization, Y.Y., Y.I. and K.U.; methodology, Y.Y. and Y.I.; validation, Y.Y., Y.I. and K.U.; formal analysis, Y.Y.; investigation, Y.Y. and Y.I.; resources, Y.Y.; data curation, Y.Y. and Y.I.; writing—original draft preparation, Y.Y.; writing—review and editing, Y.Y., Y.I., K.U.; visualization, Y.Y.; supervision, K.U.; project administration, K.U.; funding acquisition, Y.Y. All authors have read and agreed to the published version of the manuscript.

Funding: This research was funded by Pro Natura Foundation Japan: 28th Pro Natura Fund Domestic Research.

Institutional Review Board Statement: Not applicable.

Data Availability Statement: All data analyzed in this study are included in this article and appendix.

Acknowledgments: We thank Tsuyoshi Yoshimura sincerely for all the contributions on this research project.

Conflicts of Interest: The authors declare no conflict of interest.

\section{Appendix A}

Table A1. Number of monitoring trees for infestation by Aromia bungii, according to tree characteristics during the pre-and post-surveys for infestation in each study site.

\begin{tabular}{|c|c|c|c|c|c|c|c|c|}
\hline \multirow[b]{3}{*}{$\begin{array}{c}\text { Tree } \\
\text { Characteristic }\end{array}$} & \multirow{3}{*}{$\begin{array}{l}\text { Level } \\
\text { or } \\
\text { Class }\end{array}$} & \multicolumn{7}{|c|}{ Number of Monitoring Trees } \\
\hline & & \multicolumn{3}{|c|}{ Study Site Category 1} & \multicolumn{4}{|c|}{ Study Site Category 3} \\
\hline & & $\begin{array}{l}\text { Infested } \\
\text { in } \\
\text { Post- } \\
\text { Survey }\end{array}$ & $\begin{array}{c}\text { Uninfested } \\
\text { in } \\
\text { Post- } \\
\text { Survey }\end{array}$ & $\begin{array}{c}\begin{array}{c}\text { Total } \\
\text { for }\end{array} \\
\text { Analysis }\end{array}$ & $\begin{array}{l}\text { Infested } \\
\text { in } \\
\text { Pre- } \\
\text { Survey }\end{array}$ & $\begin{array}{c}\text { Infested } \\
\text { in } \\
\text { Post- } \\
\text { Survey }\end{array}$ & $\begin{array}{c}\text { Uninfested } \\
\text { in } \\
\text { Post- } \\
\text { Survey }\end{array}$ & $\begin{array}{c}\text { Total } \\
\text { for Analysis }\end{array}$ \\
\hline \multirow{3}{*}{$\begin{array}{c}\text { Bark } \\
\text { roughness }\end{array}$} & Smooth & 5 & 70 & 75 & 12 & 17 & 56 & 73 \\
\hline & Intermediate & 48 & 194 & 242 & 90 & 67 & 107 & 174 \\
\hline & Rough & 32 & 40 & 72 & 30 & 21 & 8 & 29 \\
\hline \multirow{4}{*}{ Species } & Cerasus jamasakura & 1 & 7 & 8 & 0 & 2 & 12 & 14 \\
\hline & C. Sato-zakura group & 1 & 44 & 45 & 15 & 10 & 44 & 54 \\
\hline & C. speciosa & 8 & 37 & 45 & 4 & 7 & 11 & 18 \\
\hline & $\begin{array}{l}\text { C. } \times \text { yedoensis } \\
\text { 'Somei-yoshino' }\end{array}$ & 75 & 216 & 291 & 113 & 86 & 104 & 190 \\
\hline
\end{tabular}


Table A1. Cont.

\begin{tabular}{|c|c|c|c|c|c|c|c|c|}
\hline \multirow[b]{3}{*}{$\begin{array}{c}\text { Tree } \\
\text { Characteristic }\end{array}$} & \multirow{3}{*}{$\begin{array}{l}\text { Level } \\
\text { or } \\
\text { Class }\end{array}$} & \multicolumn{7}{|c|}{ Number of Monitoring Trees } \\
\hline & & \multicolumn{3}{|c|}{ Study Site Category 1} & \multicolumn{4}{|c|}{ Study Site Category 3} \\
\hline & & $\begin{array}{l}\text { Infested } \\
\text { in } \\
\text { Post- } \\
\text { Survey }\end{array}$ & $\begin{array}{c}\text { Uninfested } \\
\text { in } \\
\text { Post- } \\
\text { Survey }\end{array}$ & $\begin{array}{l}\text { Total } \\
\text { for } \\
\text { Analysis }\end{array}$ & $\begin{array}{c}\text { Infested } \\
\text { in } \\
\text { Pre- } \\
\text { Survey }\end{array}$ & $\begin{array}{l}\text { Infested } \\
\text { in } \\
\text { Post- } \\
\text { Survey }\end{array}$ & $\begin{array}{c}\text { Uninfested } \\
\text { in } \\
\text { Post- } \\
\text { Survey }\end{array}$ & $\begin{array}{c}\text { Total } \\
\text { for Analysis }\end{array}$ \\
\hline \multirow{12}{*}{ Tree size $(\mathrm{cm})$} & $1-10$ & 0 & 15 & 15 & 0 & 0 & 11 & 11 \\
\hline & $11-20$ & 1 & 37 & 38 & 9 & 12 & 56 & 77 \\
\hline & $21-30$ & 7 & 83 & 90 & 29 & 25 & 48 & 102 \\
\hline & $31-40$ & 15 & 82 & 97 & 43 & 32 & 38 & 113 \\
\hline & $41-50$ & 30 & 52 & 82 & 27 & 16 & 14 & 57 \\
\hline & $51-60$ & 18 & 21 & 39 & 13 & 13 & 1 & 27 \\
\hline & $61-70$ & 7 & 8 & 15 & 5 & 6 & 3 & 14 \\
\hline & $71-80$ & 5 & 2 & 7 & 2 & 1 & 0 & 3 \\
\hline & $81-90$ & 0 & 1 & 1 & 2 & 0 & 0 & 2 \\
\hline & $91-100$ & 1 & 2 & 3 & 0 & 0 & 0 & 0 \\
\hline & $101-110$ & 1 & 1 & 2 & 1 & 0 & 0 & 1 \\
\hline & $111-120$ & 0 & 0 & 0 & 1 & 0 & 0 & 1 \\
\hline \multirow{4}{*}{$\begin{array}{c}\text { Tree vigor } \\
\text { (crown rating) }\end{array}$} & Level 2 & 7 & 10 & 17 & 27 & 17 & 20 & 37 \\
\hline & Level 3 & 11 & 62 & 73 & 49 & 28 & 45 & 73 \\
\hline & Level 4 & 32 & 112 & 144 & 46 & 42 & 66 & 108 \\
\hline & Level 5 & 35 & 120 & 155 & 10 & 18 & 40 & 58 \\
\hline
\end{tabular}

\section{Appendix B}

Table A2. Number of monitoring trees for infestation by Aromia bungii, classified by species, varieties, or cultivars (scientific name) during the pre- and post-surveys for infestation in each study site.

\begin{tabular}{|c|c|c|c|c|c|c|}
\hline \multirow[b]{2}{*}{$\begin{array}{l}\text { Species, Varieties, or Cultivars } \\
\text { (Scientific Name) }\end{array}$} & \multicolumn{2}{|c|}{ Study Site Category 1} & \multicolumn{3}{|c|}{ Study Site Category 3} & \multirow{2}{*}{$\begin{array}{c}\text { Total Number of } \\
\text { Monitoring Trees } \\
\text { in } \\
\text { Pre- } \\
\text { Survey }\end{array}$} \\
\hline & $\begin{array}{l}\text { Infested } \\
\text { in } \\
\text { Post- } \\
\text { Survey }\end{array}$ & $\begin{array}{c}\text { Uninfested } \\
\text { in } \\
\text { Post- } \\
\text { Survey }\end{array}$ & $\begin{array}{c}\text { Infested } \\
\text { in } \\
\text { Pre- } \\
\text { Survey }\end{array}$ & $\begin{array}{c}\text { Infested } \\
\text { in } \\
\text { Post- } \\
\text { Survey }\end{array}$ & $\begin{array}{c}\text { Uninfested } \\
\text { in } \\
\text { Post- } \\
\text { Survey }\end{array}$ & \\
\hline Cerasus itosakura 'Pendula' & 0 & 5 & 0 & 0 & 1 & 6 \\
\hline C. jamasakura & 1 & 7 & 0 & 2 & 12 & 22 \\
\hline C. leveilleana & 0 & 3 & 0 & 0 & 3 & 6 \\
\hline C. leveilleana 'Juzukakezakura' & 0 & 1 & 0 & 0 & 0 & 1 \\
\hline C. sargentii & 0 & 2 & 2 & 1 & 4 & 9 \\
\hline C. Sato-zakura Group & 0 & 15 & 8 & 7 & 31 & 61 \\
\hline C. Sato-zakura Group 'Albo-rosea' & 0 & 8 & 0 & 0 & 0 & 8 \\
\hline C. Sato-zakura Group 'Beni-yutaka' & 0 & 1 & 0 & 0 & 0 & 1 \\
\hline C. Sato-zakura Group 'Hisakura' & 0 & 0 & 0 & 1 & 0 & 1 \\
\hline C. Sato-zakura Group 'Sekiyama' & 1 & 4 & 0 & 0 & 0 & 5 \\
\hline C. speciosa & 8 & 37 & 4 & 7 & 11 & 67 \\
\hline C. speciosa 'Surugadai-odora' & 0 & 5 & 0 & 0 & 5 & 10 \\
\hline C. $\times$ yedoensis 'Somei-yoshino' & 75 & 216 & 113 & 86 & 104 & 594 \\
\hline N.A. & 0 & 0 & 5 & 1 & 0 & 6 \\
\hline
\end{tabular}

\section{Appendix C}

Table A3. Regression coefficients of the ordered categorical variables in the prediction model (GLMM) for tree infestation by Aromia bungii in uninvaded areas.

\begin{tabular}{cccccc}
\hline Explanatory Variable & Estimate & Std. Error & $z$ Value & $\operatorname{Pr}(>|z|)$ & \\
\hline Bark roughness.L. & 0.763 & 0.461 & 1.653 & 0.098 & $*$ \\
Bark roughness.Q. & 0.642 & 0.326 & 1.971 & 0.049 & $*$ \\
Tree vigor.L. & -1.295 & 0.520 & -2.489 & 0.013 & $*$ \\
Tree vigor.Q. & 0.395 & 0.420 & 0.939 & 0.348 & \\
Tree vigor.C. & -0.393 & 0.352 & -1.117 & 0.264 & \\
\hline
\end{tabular}

Explanatory variables in the GLMM formula: bark roughness + tree size + tree vigor + $(0+$ tree size I study site $)$ ${ }^{*} p<0.05, . p<0.1$. 


\section{Appendix D}

Table A4. Mean squares for variance and Chi-square values of each fixed effect based on the best model (GLMM) for tree infestation by Aromia bungii in uninvaded areas.

\begin{tabular}{cccccc}
\hline Fixed Effect & Df & $\begin{array}{c}\text { Sum of Squares } \\
\text { for Variance }\end{array}$ & $\begin{array}{c}\text { Mean Squares } \\
\text { for Variance }\end{array}$ & $\begin{array}{c}\text { Chi-Square } \\
\text { Values }\end{array}$ & Pr (>Chisq) \\
\hline Bark & 2 & 13.02 & 6.51 & 9.44 & 0.007 \\
roughness & 1 & 15.18 & 15.18 & 19.48 & $<0.001$ \\
Tree size & 1 & 6.88 & 2.29 & 6.74 & 0.081 \\
Tree vigor & 3 & &
\end{tabular}

Explanatory variables in the GLMM formula: bark roughness + tree size + tree vigor + $(0+$ tree size I study site).

\section{Appendix E}

Table A5. Regression coefficients of the ordered categorical variables in the prediction model (GLMM) for tree infestation by Aromia bungii in invaded areas.

\begin{tabular}{cccccc}
\hline Explanatory Variable & Estimate & Std. Error & $z$ Value & \multicolumn{2}{c}{$\operatorname{Pr}(>|z|)$} \\
\hline Bark roughness.L. & 1.205 & 0.504 & 2.392 & 0.017 & $*$ \\
Bark roughness.Q. & 0.609 & 0.326 & 1.867 & 0.062 &. \\
Cerasus × yedoensis & 0.402 & 0.618 & 0.651 & 0.515 & \\
'Somei-yoshino' & -0.490 & 0.765 & -0.641 & 0.522 & \\
C. Sato-zakura group & -1.695 & 1.146 & -1.480 & 0.139 & \\
C. jamasakura & -1.312 & 0.421 & -3.114 & 0.002 & $*$ \\
Tree vigor.L. & 0.135 & 0.344 & 0.394 & 0.694 & \\
Tree vigor.Q. & -0.072 & 0.296 & -0.242 & 0.809 & \\
Tree vigor.C. &
\end{tabular}

Explanatory variables in the GLMM formula: bark roughness + species + tree size + tree vigor + $(0+$ tree size study site). ${ }^{* *} p<0.01,{ }^{*} p<0.05, . p<0.1$.

\section{Appendix F}

Table A6. Mean squares for variance and Chi-square values of each fixed effect based on the best model (GLMM) for tree infestation by Aromia bungii in invaded areas.

\begin{tabular}{cccccc}
\hline Fixed Effect & Df & $\begin{array}{c}\text { Sum of Squares } \\
\text { for Variance }\end{array}$ & $\begin{array}{c}\text { Mean Squares } \\
\text { for Variance }\end{array}$ & $\begin{array}{c}\text { Chi-Square } \\
\text { Values }\end{array}$ & $\operatorname{Pr}(>$ Chisq) \\
\hline Bark & 2 & 11.82 & 5.91 & 6.48 & 0.039 \\
roughness & 3 & 6.21 & 2.07 & 6.93 & 0.074 \\
Species & 1 & 16.53 & 16.53 & 22.63 & $<0.001$ \\
Tree size & 1 &
\end{tabular}

Explanatory variables in the GLMM formula: bark roughness + tree size + tree vigor + (0 + tree size I study site).

\section{References}

1. EPPO. EPPO datasheet on pests recommended for regulation Aromia bungii. EPPO Bull. 2015, 45, 4-8. [CrossRef]

2. Iwata, R. Aromia bungii (Coleoptera: Cerambycidae): Taxonomy, distribution, biology and eradication. For. Pests 2018, 67, 7-34. (In Japanese)

3. EFSA. Aromia bungii Pest Report to Support Ranking of EU Candidate Priority Pests; Pest Report EN-1639; EFSA: Parma, Italy, 2019; pp. 1-33. [CrossRef]

4. Russo, E.; Nugnes, F.; Vicinanza, F.; Garonna, A.P.; Bernardo, U. Biological and molecular characterization of Aromia bungii (Faldermann, 1835) (Coleoptera: Cerambycidae), an emerging pest of stone fruits in Europe. Sci. Rep. 2020, 10, 7112. [CrossRef] [PubMed]

5. Lockwood, J.L.; Hoopes, M.F.; Marchetti, M.P. Eradication and control of invaders. In Invasion Ecology, 2nd ed.; Wiley-Blackwell: Chichester, UK, 2013; pp. 335-355.

6. Fan, J.T.; Denux, O.; Courtin, C.; Bernard, A.; Javal, M.; Millar, J.G.; Hanks, L.M.; Roques, A. Multi-component blends for trapping native and exotic longhorn beetles at potential points-of-entry and in forests. J. Pest Sci. 2019, 92, 281-297. [CrossRef] 
7. Millar, J.G.; Zou, Y.; Barringer, L.; Hanks, L.M. Field trials with blends of pheromones of native and invasive Cerambycid beetle species. Environ. Entomol. 2021, 50, 1294-1298. [CrossRef]

8. Xu, T.; Yasui, H.; Teale, S.A.; Fujiwara-Tsujii, N.; Wickham, J.D.; Fukaya, M.; Hansen, L.; Kiriyama, S.; Hao, D.; Nakano, A.; et al Identification of male-produced sex-aggregation pheromone for a highly invasive cerambycid beetle, Aromia bungii. Sci. Rep. 2017, 7, 7330. [CrossRef] [PubMed]

9. Di Palma, A.; Pistillo, M.; Griffo, R.; Garonna, A.P.; Germinara, G.S. Scanning electron microscopy of the antennal sensilla and their secretion analysis in adults of Aromia bungii (Faldermann, 1835) (Coleoptera, Cerambycidae). Insects 2019, 10, 88. [CrossRef] [PubMed]

10. Germinara, G.S.; Pistillo, M.; Griffo, R.; Garonna, A.P.; Di Palma, A. Electroantennographic responses of Aromia bungii (Faldermann, 1835) (Coleoptera, Cerambycidae) to a range of volatile compounds. Insects 2019, 10, 274. [CrossRef]

11. Fukaya, M.; Kiriyama, S.; Yasui, H. Mate-location flight of the red-necked longicorn beetle, Aromia bungii (Coleoptera: Cerambycidae): An invasive pest lethal to Rosaceae trees. Appl. Entomol. Zool. 2017, 52, 559-565. [CrossRef]

12. Yasui, H.; Fujiwara-Tsujii, N.; Kugimiya, S.; Haruyama, N. Extension of sustained pheromone release for monitoring an emerging invader, red-necked longicorn Beetle Aromia bungii (Coleoptera: Cerambycidae). Appl. Entomol. Zool. 2021, 56, 291-297. [CrossRef]

13. Ito, K. Differential host residence of adult cryptomeria bark borer, Semanotus japonicus Lacordaire (Coleoptera: Cerambycidae), in relation to tree size of Japanese cedar, Cryptomeria japonica D. Don. J. For. Res. 1999, 4, 151-156. [CrossRef]

14. Nahrung, H.F.; Smith, T.E.; Wiegand, A.N.; Lawson, S.A.; Debuse, V.J. Host tree influences on longicorn beetle (Coleoptera: Cerambycidae) attack in subtropical Corymbia (Myrtales: Myrtaceae). Environ. Entomol. 2014, 43, 37-46. [CrossRef]

15. Nelson, T.D.; Sweeney, J.D.; Hillier, N.K. Do visual cues associated with larger diameter trees influence host selection by Tetropium fuscum (Coleoptera: Cerambycidae)? Can. Entomol. 2017, 149, 487-490. [CrossRef]

16. Morewood, W.D.; Neiner, P.R.; McNeil, J.R.; Sellmer, J.C.; Hoover, K. Oviposition preference and larval performance of Anoplophora glabripennis (Coleoptera: Cerambycidae) in four eastern North American hardwood tree species. Environ. Entomol. 2003, 32, 1028-1034. [CrossRef]

17. Hanks, L.M. Influence of the larval host plant on reproductive strategies of Cerambycid beetles. Annu. Rev. Entomol. 1999, 44, 483-505. [CrossRef]

18. Saint-Germain, M.; Buddle, C.M.; Drapeau, P. Primary attraction and random landing in host selection by wood-feeding insects: A matter of scale? Agric. For. Entomol. 2007, 9, 227-235. [CrossRef]

19. Flaherty, L.; Quiring, D.; Pureswaran, D.; Sweeney, J. Preference of an exotic wood borer for stressed trees is more attributable to pre-alighting than post-alighting behaviour. Ecol. Entomol. 2013, 38, 546-552. [CrossRef]

20. Shibata, E.; Waguchi, Y.; Yoneda, Y. Role of tree diameter in the damage caused by the sugi bark borer (Coleoptera: Cerambycidae) to the Japanese cedar, Cryptomeria japonica. Environ. Entomol. 1994, 23, 76-79. [CrossRef]

21. Menzel, F.; Kitching, R.L.; Boulter, S.L. Host specificity or habitat structure? The epicortical beetle assemblages in an Australian subtropical rainforest. Eur. J. Entomol. 2004, 101, 251-259. [CrossRef]

22. Kašák, J.; Foit, J. Shortage of declining and damaged sun-exposed trees in European mountain forests limits saproxylic beetles: A case study on the endangered longhorn beetle Ropalopus ungaricus (Coleoptera: Cerambycidae). J. Insect Conserv. 2018, 22, 171-181. [CrossRef]

23. Haruyama, N.; Yaita, S.; Fukuda, T.; Yamazaki, K.; Watanabe, H.; Handa, M. Peach orchard damages caused by the red-necked longhorn beetle Aromia bungii (Faldermann) in Tochigi Prefecture. Ann. Rep. Kanto-Tosan. Plant. Prot. Soc. 2019, 66, 106-109. (In Japanese) [CrossRef]

24. Yamamoto, Y.; Ishikawa, Y. Occurrence of Aromia bungii in Osaka Prefecture. Ann. Rept. Kansai. Plant Prot. 2018, 60, 17-21. [CrossRef]

25. Tamura, S.; Sunamura, E.; Shoda-Kagaya, E. Seasonal changes in frass ejection by larval red-necked longicorn beetles, Aromia bungii (Coleoptera: Cerambycidae), infesting cherry trees. Jpn. J. Appl. Entomol. Zool. 2021, 65, 57-61. [CrossRef]

26. Shoda-Kagaya, E. Cherry tree damages associated with the invasion of red-necked longhorn beetle Aromia bungii in Japan. Tree Health 2015, 19, 37-40. (In Japanese) [CrossRef]

27. Yamamoto, Y.; Uehara, K.; Ishikawa, Y.; Tsuyoshi, Y. Survey on the actual damage by the invasive red-necked longhorn beetle (Aromia bungii) harmful to trees such as the Japanese flowering cherries. A. R. Pro. Nat. Found. Ja. 2019, 8, 24-35. (In Japanese) [CrossRef]

28. Rizzo, D.; Luchi, N.; Da Lio, D.; Bartolini, L.; Nugnes, F.; Cappellini, G.; Bruscoli, T.; Salemi, C.; Griffo, R.V.; Garonna, A.P.; et al. Development of a loop-mediated isothermal amplification (LAMP) assay for the identification of the invasive wood borer Aromia bungii (Coleoptera: Cerambycidae) from frass. 3 Biotech 2021, 11, 85. [CrossRef]

29. Ishikawa, Y. Notes on the frass of longicorn beetles on Cerasus (Prunus) tree. Plant Prot. 2021, 75, 557-563. (In Japanese)

30. Yasuoka, T. Efficacy of insecticides against larvae of red necked longhorn beetle Aromia bungii (Faldermann) (Coleoptera: Cerambycidae). Res. Bull. Plant Prot. Japan. 2017, 53, 51-62. (In Japanese)

31. Yamamoto, Y. Invasion and control strategy of the red-necked longhorn beetle Aromia bungii. J. Pestic. Sci. 2010, 45, 127-133. [CrossRef]

32. Hishinuma, S.; Coleman, T.W.; Flint, M.L.; Seybold, S.J. Goldspotted Oak Borer: Field Identification Guide. University of California Agriculture and Natural Resources, Statewide Integrated Pest Management Program. 2011. Available online: https://www.fs.fed.us/psw/publications/seybold/psw_2011_seybold(hishinuma)001.pdf (accessed on 31 October 2021). 
33. Oohara, T. The Handbook of Flowering Cherries in Japan, 1st ed.; Bun-Ichi Co., Ltd.: Tokyo, Japan, 2009; pp. 1-88. (In Japanese)

34. Katsuki, T. Taxonomy and identification by morphology for Japanese flowering cherries. Tree Health 2017, 21, 93-104. (In Japanese) [CrossRef]

35. R: A Language and Environment for Statistical Computing. Available online: https://www.R-project.org/ (accessed on 31 March 2021).

36. Akaike, H. A new look at the statistical model identification. IEEE Trans. Autom. Contr. 1974, 19, 716-723. [CrossRef]

37. Hardersen, S.; Cuccurullo, A.; Bardiani, M.; Bologna, M.A.; Maura, M.; Maurizi, E.; Roversi, P.F.; Sabbatini Peverieri, G.; Chiari, S. Monitoring the saproxylic longhorn beetle Morimus asper: Investigating season, time of the day, dead wood characteristics and odour traps. J. Insect Conserv. 2017, 21, 231-242. [CrossRef]

38. Byers, J.A. An encounter rate model of bark beetle populations searching at random for susceptible host trees. Ecol. Model. 1996, 91, 57-66. [CrossRef]

39. Ferrenberg, S.; Mitton, J.B. Smooth bark surfaces can defend trees against insect attack: Resurrecting a "slippery" hypothesis. Funct. Ecol. 2014, 28, 837-845. [CrossRef]

40. Eyre, D.; Haack, R.A. Invasive cerambycid pests and biosecurity measures. In Cerambycidae of the World: Biology and Pest Management; Wang, Q., Ed.; CRC Press: Boca Raton, FL, USA, 2017; pp. 563-618.

41. Faccoli, M.; Favaro, R. Host preference and host colonization of the Asian long-horned beetle, Anoplophora glabripennis (Coleoptera Cerambycidae), in Southern Europe. Bull. Entomol. Res. 2016, 106, 359-367. [CrossRef] 